Marquette University

e-Publications@Marquette

Biomedical Engineering Faculty Research and

Publications

Biomedical Engineering, Department of

6-1-1997

\title{
Experimental Spinal Fusion With Recombinant Human Bone Morphogenetic Protein-2 Without Decortication of Osseous Elements
}

\author{
Harvinder Sandhu \\ Cornell University Medical College \\ Linda E.A. Kanim \\ UCLA School of Medicine \\ Jeffrey M. Toth \\ Marquette University, jeffrey.toth@marquette.edu \\ J. Michael Kabo \\ UCLA School of Medicine \\ David Liu \\ UCLA School of Medicine
}

See next page for additional authors

Follow this and additional works at: https://epublications.marquette.edu/bioengin_fac

Part of the Biomedical Engineering and Bioengineering Commons

\section{Recommended Citation}

Sandhu, Harvinder; Kanim, Linda E.A.; Toth, Jeffrey M.; Kabo, J. Michael; Liu, David; Delamarter, Rick B.; and Dawson, Edgar G., "Experimental Spinal Fusion With Recombinant Human Bone Morphogenetic Protein-2 Without Decortication of Osseous Elements" (1997). Biomedical Engineering Faculty Research and Publications. 568.

https://epublications.marquette.edu/bioengin_fac/568 


\section{Authors}

Harvinder Sandhu, Linda E.A. Kanim, Jeffrey M. Toth, J. Michael Kabo, David Liu, Rick B. Delamarter, and Edgar G. Dawson

This article is available at e-Publications@Marquette: https://epublications.marquette.edu/bioengin_fac/568 
Marquette University

e-Publications@Marquette

\section{Biomedical Engineering Faculty Research and Publications/College of Engineering}

This paper is NOT THE PUBLISHED VERSION; but the author's final, peer-reviewed manuscript. The published version may be accessed by following the link in the citation below.

Spine, Vol. 22, No. 11 (June, 1997): 1171-1180. Permalink. This article is (C) Lippincott Williams \& Wilkins, Inc. and permission has been granted for this version to appear in e-Publications@Marquette. Lippincott Williams \& Wilkins, Inc. does not grant permission for this article to be further copied/distributed or hosted elsewhere without the express permission from Lippincott Williams \& Wilkins, Inc.

\section{Experimental Spinal Fusion With Recombinant Human Bone Morphogenetic Protein-2 Without Decortication of Osseous Elements}

Sandhu, Harvinder S.

Department of Orthopaedic Surgery and the UCLA Comprehensive Spine Center, UCLA School of Medicine, Los Angeles, CA

Kanim, Linda E.A.

Department of Orthopaedic Surgery and the UCLA Comprehensive Spine Center, UCLA School of Medicine, Los Angeles, CA

Toth, Jeffrey $M$.

Department of Orthopaedic Surgery, The Medical College of Wisconsin, Milwaukee, WI

Kabo, J. Michael

Department of Orthopaedic Surgery and the UCLA Comprehensive Spine Center, UCLA School of Medicine, Los Angeles, CA

Liu, David 
Department of Orthopaedic Surgery and the UCLA Comprehensive Spine Center, UCLA School of Medicine, Los Angeles, CA

Delamarter, Rick B.

Department of Orthopaedic Surgery and the UCLA Comprehensive Spine Center, UCLA School of Medicine, Los Angeles, CA

Dawson, Edgar G.

Department of Orthopaedic Surgery and the UCLA Comprehensive Spine Center, UCLA School of Medicine, Los Angeles, CA

\section{Keywords:}

bone induction; bone morphogenetic protein; canine; decortication; polylactic acid polymer; posterolateral fusion; recombinant bone morphogenetic protein-2; spine fusion technique

\section{Abstract:}

Study Design. L4-L5 intertransverse process fusions were produced with $58 \mu \mathrm{g}, 230 \mu \mathrm{g}$, or $920 \mu \mathrm{g}$ of recombinant human bone morphogenetic protein-2 in 20 dogs. Eleven had traditional decortication of posterior elements before insertion of the implant. Nine were left undecorticated. All animals were evaluated 3 months after surgery.

Objectives. To determine whether decortication is a prerequisite for successful fusion in the presence of osteoinductive proteins such as bone morphogenetic protein-2.

Summary of Background Data. Recombinant osteoinductive proteins can induce de novo bone in ectopic soft-tissue sites in the absence of bone marrow elements. Traditional methods for achieving spinal fusion rely on exposure of bone marrow through decortication to facilitate osteogenesis. It is hypothesized that the presence of an implanted osteoinductive protein obviates the need for exposure and release of host inductive factors.

Methods. Recombinant human bone morphogenetic protein-2-induced intertransverse process fusions were performed with and without decortication. Fusion sites were evaluated by computed tomography imaging, high-resolution radiography, manual testing, mechanical testing, and histologic analysis.

Results. One hundred percent of decorticated spines and $89 \%$ of undecorticated spines were clinically fused by 3 months. Ninety-one percent of decorticated spines and $78 \%$ of undecorticated specimens exhibited bilateral transverse process osseous bridging. The only spines that failed to achieve solid bilateral arthrodesis were in the lowest dose group. With the higher two doses, there was histologic evidence of osseous continuity between the fusion mass and undecorticated transverse processes.

Conclusions. There were no statistical differences in clinical and radiographic fusion rates between decorticated and undecorticated sites. With higher doses of recombinant human bone morphogenetic protein-2, there was little histologic distinction between fusions in decorticated versus undecorticated spines. 
In 1924, Russell Hibbs ${ }^{-6}$ first described the technique of "denuding" or decorticating facet and laminar elements before placement of autologous bone graft for induction of posterior spinal fusion. Subsequently, in 1927 Willis Cambell 3 advocated the use of transverse processes as an additional recipient site for onlay graft. The biologic justification for decortication has been that opening of the intramedullary space of the transverse processes, facets, lamina, pedicles, or vertebral bodies exposes local bone marrow to the fusion site. $\underline{10}$ The exposed marrow, it is believed, provides the fusion bed with osteoinductive proteins, cells of the inflammatory response, a local blood supply including the initial hematoma, and potential osteogenic cells. ${ }^{5,10}$ For this reason, most spine surgeons have preferred decortication as a method of facilitating posterior fusion.

Nevertheless, there are several disadvantages with this technique. Additional exposure sometimes is required to properly access posterior elements with decorticating instruments. The procedure generally increases operative time and blood loss and potentially increases postoperative pain, the requirement for postoperative drainage, and the risk of neurologic injury. In some cases, decortication may weaken the purchase sites for internal fixation devices. As a consequence, some authors have recommended excluding this step and its associated morbidity in exchange for an increased risk of pseudarthrosis. $\frac{1,8}{}$

The recent availability of recombinantly produced osteoinductive cytokines such as bone morphogenetic protein has enabled investigators to manipulate the biologic environments of orthotopic sites. $\frac{16,17}{1}$ Since introducing the concept of osteogenic bone proteins in 1965 , Urist $\frac{13-15}{15}$ has demonstrated the ability of bone morphogenetic protein to induce the differentiation of pluripotent precursor cells along an osteogenic line. Recombinant bone morphogenetic protein-2 (rhBMP-2) has, in fact, induced de novo formation of cartilage and bone in subcutaneous sites in the absence of marrow elements. $\underline{17}$ Recombinant bone morphogenetic protein-2 also has effectively induced solid posterior and posterolateral lumbar arthrodesis in dogs and rabbits in decorticated fusion models. $\underline{11,12}$

The hypothesis of this study is that, as in ectopic osteogenesis, rhBMP-2 may not require marrow elements to effect solid lumbar transverse process arthrodesis. As such, decortication and exposure of marrows may not be a necessary step in lumbar fusion surgery in the presence of rhBMP- 2 .

\section{Materials and Methods}

Design. Twenty mature female beagles undergoing L4-L5 posterolateral transverse process fusions are reported. Before insertion of the osteoinductive implant, the posterior elements, including the transverse processes, facet joints, and lamina, were either decorticated or left intact (undecorticated). The dogs received implants containing either $58 \mu \mathrm{g}, 230 \mu \mathrm{g}$, or $920 \mu \mathrm{g}$ of rhBMP-2 (Table 1). No internal fixation was used nor were the animals immobilized after surgery. The surgeon was not aware of the subject's assignment until the time of fusion bed preparation. All animals were killed 3 months after surgery. 


\begin{tabular}{lcc}
\hline Condition & $\begin{array}{c}\text { rhBMP-2 Dose } \\
(\mu \mathrm{g})\end{array}$ & No. of Animals \\
\hline Decorticated & 920 & 3 \\
& 230 & 4 \\
Total & 58 & 4 \\
Undecorticated & & 11 \\
& 920 & 3 \\
Total & 230 & 3 \\
& 58 & 3 \\
\hline
\end{tabular}

$\underline{\text { Table } 1}$

Materials. The delivery vehicle for the recombinant protein was a porous (open-cell) polylactic acid polymer (OPLA). Only $7 \%$ of the volume of the device consisted of the polymer; the remainder was void space. The device was sterilized by 2.9 Mrad gamma irradiation and provided as $12.0 \mathrm{~mm} \times 6.0 \mathrm{~mm} \times$ $30.0 \mathrm{~mm}$ rectangular strips (supplied by Sofamor Danek, Memphis, TN, developed and manufactured by THM Biomedical, Duluth, MN).

The rhBMP-2 (Genetics Institute, Andover, MA) was provided in freeze-dried form and reconstituted intraoperatively with sterile water. One cubic centimeter of solution containing $58 \mu \mathrm{g}, 230 \mu \mathrm{g}$, or 920 $\mu \mathrm{g}$ of rhBMP-2 was added to each OPLA strip by drip application to produce the composite implant. The dosing scheme and preparation of implants were the same for the decorticated and undecorticated canines.

Subjects. Mature female beagles weighing between $8.0 \mathrm{~kg}$ and $12.5 \mathrm{~kg}$ (average, $9.9 \mathrm{~kg}$ ) with an age range of 1.1 years to 2.1 years (mean age, 1.6 years) were used for evaluation. The animals were screened for systemic disease and conditioned for at least 1 week before inclusion in the study.

Surgical Procedure. Single level posterolateral transverse process fusions of the L4-L5 segmental level were performed. After halothane anesthesia and endotracheal intubation, each dog was placed prone on the operating table, and the posterior lumbar region was shaved, prepared, and draped in sterile fashion. The posterior elements were exposed through a midline incision, and the transverse processes, facet joints, and lamina were cleaned of soft tissues. A localization radiograph was taken to ensure exposure of the appropriate level. Care was taken to avoid inadvertent exposure of adjacent facet joints or transverse processes.

In dogs designated for decortication, the posterior cortices of the appropriate transverse processes, lamina, and facet joints were denuded with a power burr (Dremel Moto-Tool, Model 395, Racine, WI) until punctate bleeding was observed and marrow elements exposed. Before implantation of the osteoinductive composite, the fusion bed was irrigated thoroughly to remove residual osseous debris. 
In dogs that were not to be decorticated, the posterior elements were left intact, and the fusion bed was irrigated thoroughly.

The rhBMP-2 and OPLA carrier composites were placed into the right and left posterolateral gutters in direct apposition with each of the transverse processes of L4 and L5 spanning the space. The implants were not in contact with the lamina.

Routine closure of the dorsolumbar fascia, subcutaneous tissue, and skin was performed. Parenteral antibiotics (enrofloxacin, $2.5 \mathrm{mg} / \mathrm{kg}$ or cefazolin, $2.0 \mathrm{mg} / \mathrm{kg}$ ) were administered intraoperatively and for 72 hours after surgery.

Computed Tomography Evaluation. With the subjects under nembutal anesthesia, computed tomography (CT) scans were obtained 2 and 3 months after surgery for all animals. Axial sections of the fusion site were evaluated qualitatively for bone formation and remodeling.

Manual Testing. All dogs were killed with $0.22 \mathrm{~mL} / \mathrm{kg}$ of Euth- 6 Veterinary Solution (Western Medical Supply Co., Arcadia, CA) 3 months after surgery, and the lumbar spines were explanted. After explantation, the L4-L5 intervertebral segment was manually tested for motion. The intervertebral segment was graded as nonfusion if motion was detected in any plane. Absence of motion was considered sufficient evidence of fusion.

High Resolution Radiographic Evaluation. Using the Faxitron imaging device (Field Emission Corporation, McMinnville, OR), a high-resolution radiograph was taken of the explanted lumbar spine in the coronal plane after cleaning of soft tissues (Kodak Industrex Film, 50-13 cm × $18 \mathrm{~cm}$, \#507-2392, exposure 30 MA @ 3 minutes, Eastman Kodak Co., Rochester, NY). A radiographically successful transverse process fusion was defined as complete and uninterrupted osseous bridging of the transverse processes bilaterally. Unilateral osseous bridging or facet or interlaminar bony union was not considered a successful transverse process fusion.

Nondestructive Mechanical Testing. The mechanical tests were conducted on all but one specimen from each rhBMP-2 dose group. The testing consisted of manually applying pure torques and linear loads and then measuring the corresponding angular and linear displacements. The measurements were conducted in the following modes: flexion-extension (sagittal plane), lateral bending (coronal plane), and rotation (axial plane). For each mode, the average of the median measures for the two directional torques was used for analysis. The protocol for this testing has been described previously. $\underline{\underline{11}}$

Histology. After mechanical testing, the spinal motion segment was fixed in $10 \%$ neutral buffered formalin and bisected sagittally for histologic analysis. Both halves of the spinal segment were dehydrated sequentially in $70 \%$ alcohol for 2-3 days, 95\% alcohol for 2-3 days, two changes of $100 \%$ alcohol for 2-3 days each, and xylene for 1 day.

The explants then were embedded in methylmethacrylate and sectioned on a diamond saw (Buehler Isomet, Lake Bluff, IL) to produce at least 10 sections of an approximate thickness of $100 \mu \mathrm{m}$ to 200 
$\mu \mathrm{m}$. One side of the bisected level was sectioned in the sagittal plane, and the other side was sectioned in the axial plane. This orientation was randomized.

Undecalcified sections of the explants from this study were radiographed using Copper k-alpha radiation at $20 \mathrm{kV}$ and $30 \mathrm{~mA}$ using a microradiography unit (Kristalloflex-2, Siemens, New York, NY) and spectroscopic film (Kodak, Rochester, NY). Sections were exposed for 12.5 minutes for each $100 \mu \mathrm{m}$ of thickness. These plates then were developed, fixed, and analyzed for ossification using standard optical microscopy.

Staining was performed after microradiography to determine the quality and quantity of osteogenesis. When de novo bone was present, the distinct histogenesis (enchondral or intramembranous osteogenesis) was noted as well as the presence of woven or lamellar bone matrix. Finally, differential staining with basic fuchsin and toluidine blue- 0 was used to evaluate the histologic and cytologic host response to the implant. This included evaluating the presence or absence of an inflammatory response to the carrier, the amount and quality of bone induced by the bone morphogenetic protein, and the interface between the induced bone and native host bone. After staining, all undecalcified sections and microradiographs were read by an orthopaedic histopathologist in a blinded fashion.

Statistical Analysis. Qualitative manual testing data and radiographic data were analyzed using Fisher's exact test. Analysis of Variance (BMDP Statistical Software 2V, Cary, NC) was applied to median measures of stiffness for each mode of motion: sagittal bending, coronal bending, and axial rotation. There were two grouping factors (presence of decortication and dose).

\section{Results}

\section{Surgery}

All animals tolerated the procedures well, and no perioperative deaths occurred. Two dogs that had been decorticated and implanted with a $58 \mu \mathrm{g}$ dose of rhBMP-2 developed postoperative infections and were excluded from the study; both dogs were replaced.

The mean age at the time of surgery was 1.89 years for the undecorticated dogs and 1.52 years for the decorticated dogs $(P=0.03)$. Body weight at the time of surgery was similar between the two groups (weight, $9.5 \mathrm{~kg}$ and $10.2 \mathrm{~kg}$, respectively; $P=0.15$ ).

\section{Computerized Tomography}

Examples of CT images obtained 2 and 3 months after surgery are depicted for decorticated spines (Figure 1A-B) and for undecorticated spines (Figure 2A-B). Evidence of de novo bone formation was noted with all three doses of rhBMP-2 in decorticated and undecorticated spines by 2 months after implantation. By 3 months, there was evidence of cortical remodeling of the fusion mass in some areas. This was noted in fusions induced by all three doses of the inductive protein and in decorticated and undecorticated spines. No bone was present anterior to the transverse process plane in any spine. Although the implants had been placed laterally along the transverse processes, de novo bone was 
noted centrally along intact lamina of L4 and L5. There was no evidence of bone encroaching the spinal canal either centrally or intraforaminally, and there was no evidence of adjacent level bony bridging. No other qualitative differences were noted between the groups.
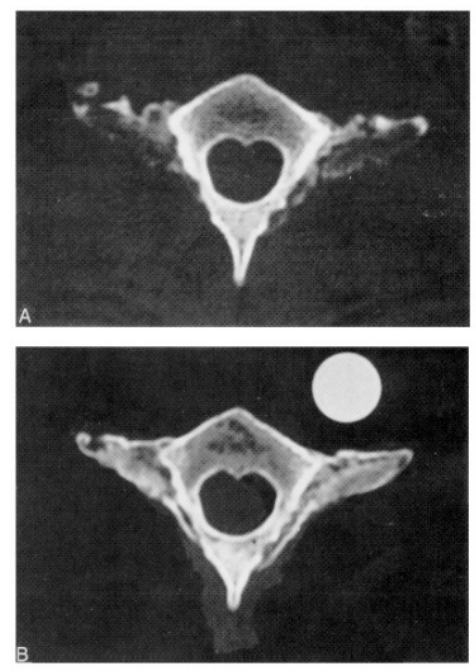

Figure 1

\section{High-Resolution Radiography}

Radiographic fusion rates are depicted in Table 2. Three spines were rated as radiographic fusion failures based on the criteria outlined above. Two of the failures were unilateral nonunions (one decorticated and one undecorticated specimen), and one was a bilateral nonunion (an undecorticated specimen). The radiographic grades were not significantly related to the state of decortication $(P=$ $0.57)$.

\begin{tabular}{lcc}
\hline Condition & $\begin{array}{c}\text { rhBMP-2 Dose } \\
(\mu \mathrm{g})\end{array}$ & $\begin{array}{c}\text { Radiographic } \\
\text { Fusions } \\
\text { no./total }\end{array}$ \\
\hline Decorticated & 920 & $3 / 3$ \\
& 230 & $4 / 4$ \\
Total & 58 & $3 / 4$ \\
Undecorticated & & $10 / 11$ \\
& 920 & $3 / 3$ \\
Total & 230 & $3 / 3$ \\
& 58 & $1 / 3$ \\
\hline
\end{tabular}




\section{Table 2}

All three radiographic failures had been implanted with the $58 \mu \mathrm{g}$ dose of rhBMP-2. No failures were noted in the two higher-dose groups. The correlation between failure and dose of rhBMP-2 was significant $(P=0.03)$

Sample high-resolution radiographs of fusion sites that had been decorticated (Figure $3 A-C$ ) and left undecorticated (Figure $4 \mathrm{~A}-\mathrm{C}$ ) are presented. In both figures, the radiograph labeled (C) depicts a fusion site that had been rated a failure because of the absence of bilateral transverse process union. There were no overt qualitative differences between successful fusions produced by either technique. On occasion, however, focal lucencies or "void" areas were noted within the fusion mass (Figure 4A, left side). The presence of such voids was not correlated with the state of decortication. No evidence of sclerosis or osteolysis was present adjacent to these areas.
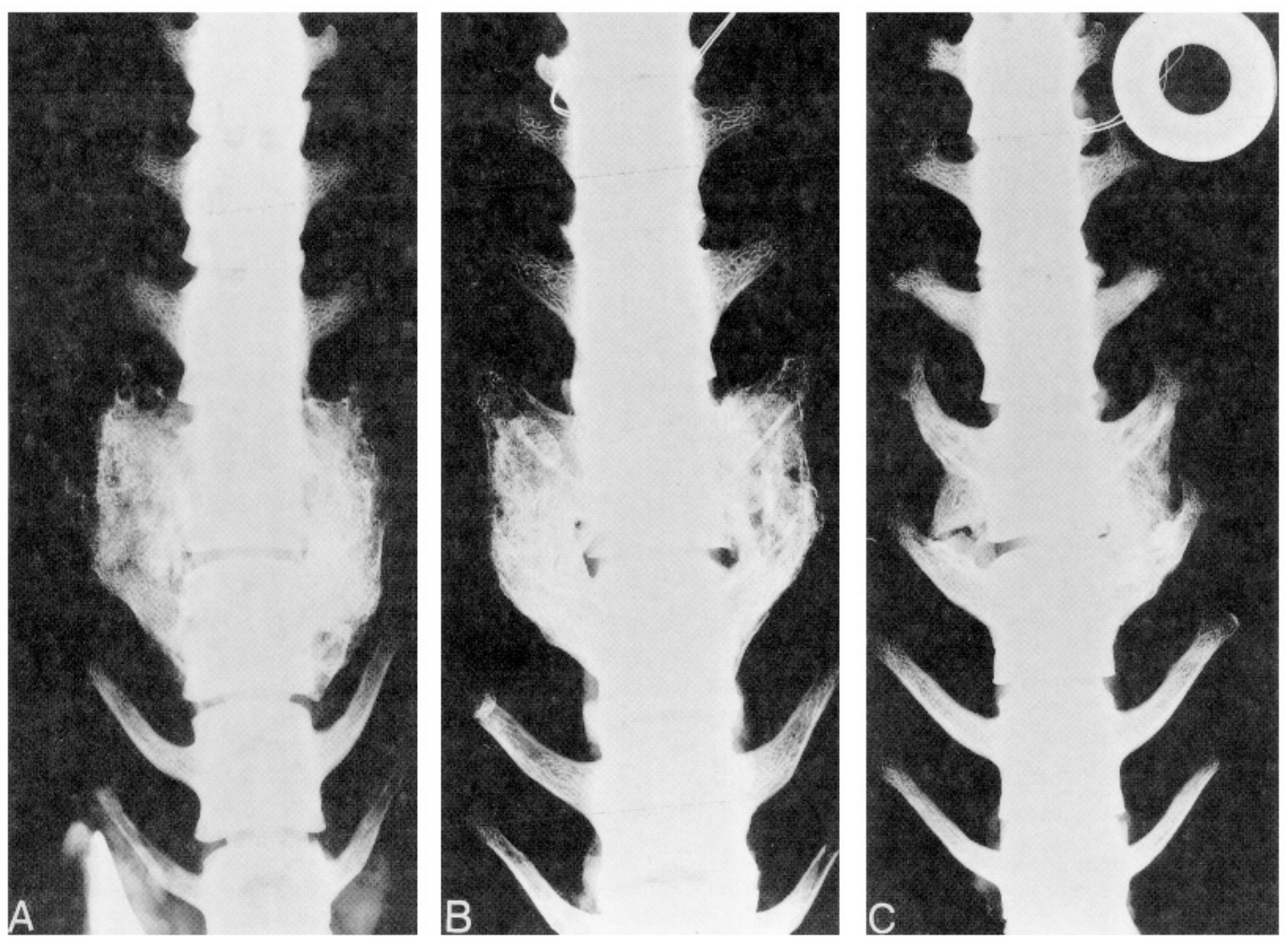

Figure 3 


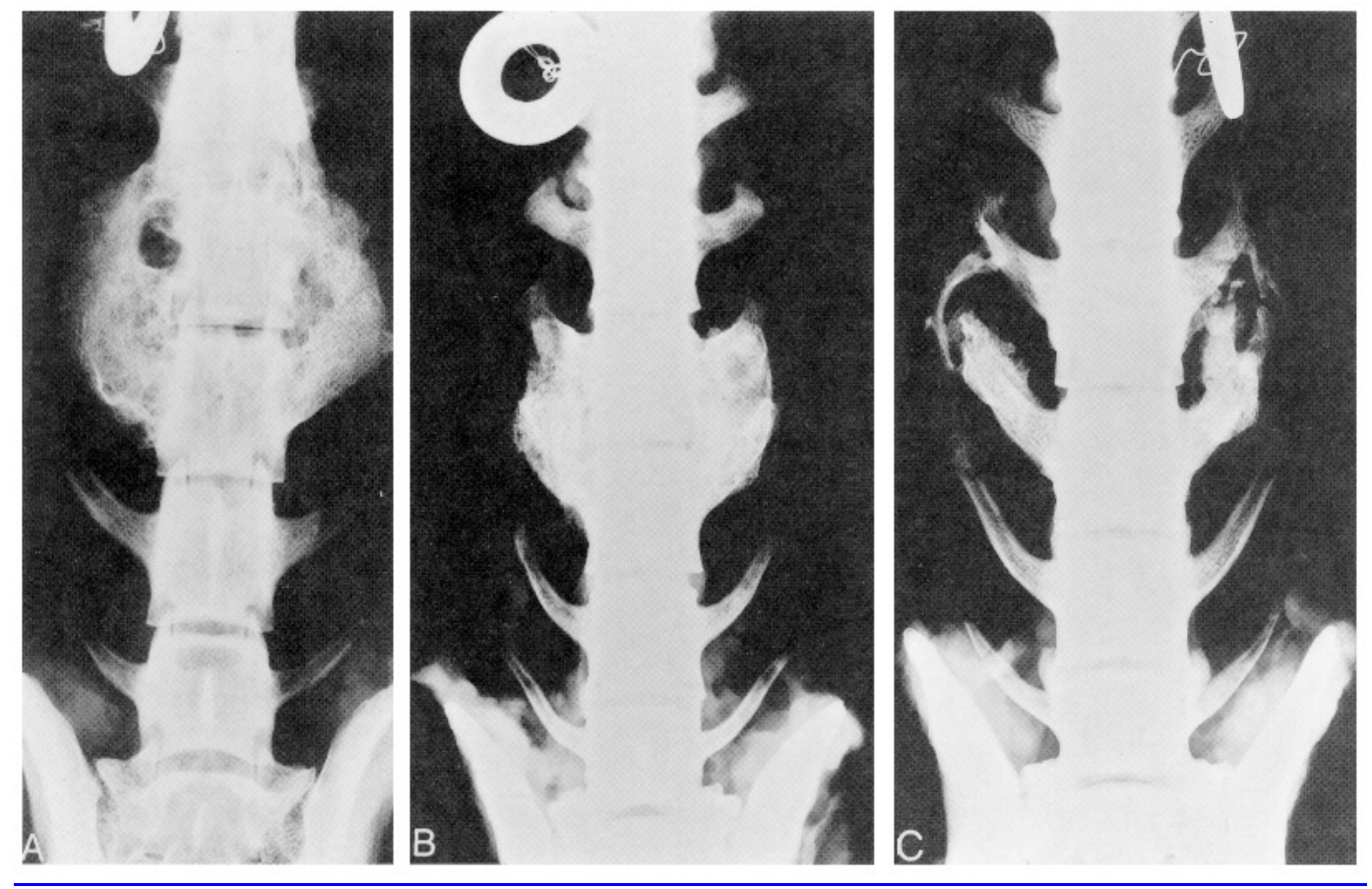

Figure 4

\section{Manual Testing}

All fusion sites except one had achieved clinical fusion based on manual manipulation of the explanted L4-L5 segment (Table 3). The exception was an undecorticated spine implanted with the $58 \mu \mathrm{g}$ dose of rhBMP-2. The fusion rates were not significantly different regardless of whether they were compared by individual dose $(58 \mu \mathrm{g}$, decorticated vs. undecorticated, $P=0.43$ ) or combined doses of rhBMP-2 (all doses, decorticated vs. undecorticated, $P=0.45$ ).

\begin{tabular}{lcc}
\hline Condition & $\begin{array}{c}\text { rhBMP-2 Dose } \\
(\mu \mathrm{g})\end{array}$ & Manual Fusions \\
\hline Decorticated & 920 & $3 / 3$ \\
& 230 & $4 / 4$ \\
Total & 58 & $4 / 4$ \\
Undecorticated & & $11 / 11$ \\
& 920 & $3 / 3$ \\
Total & 230 & $3 / 3$ \\
& 58 & $2 / 3$ \\
\hline
\end{tabular}




\section{Table 3}

\section{Mechanical Testing}

The median values for each plane of motion in each specimen were analyzed (Table 4). Combining all doses, there were no differences in mechanical stiffness to sagittal bending $(P=0.39)$, axial torque $(P=$ $0.54)$, or coronal bending $(P=0.15)$ between decorticated and undecorticated specimens.

\begin{tabular}{lcccc}
\hline & & \multicolumn{3}{c}{ Mechanical Stiffness } \\
\cline { 3 - 5 } & $\begin{array}{c}\text { rhBMP-2 } \\
\text { Dose } \\
\text { Condition }\end{array}$ & $\begin{array}{c}\text { Sagittal } \\
(\mu \mathrm{N} / \mathrm{cm})\end{array}$ & $\begin{array}{c}\text { Coronal } \\
(\mathrm{N} / \mathrm{cm})\end{array}$ & $\begin{array}{c}\text { Axial } \\
(\mathrm{N}-\mathrm{m} / \mathrm{deg})\end{array}$ \\
\hline$\overline{\mathrm{x}} \pm \mathrm{SD}$ & $\overline{\mathrm{x}} \pm \mathrm{SD}$ & $\overline{\mathrm{x}} \pm \mathrm{SD}$ \\
\hline Decorticated & 920 & $149 \pm 00$ & $131 \pm 00$ & $2.0 \pm 0.0$ \\
& 230 & $212 \pm 30$ & $248 \pm 41$ & $3.5 \pm 0.5$ \\
Average & 58 & $181 \pm 91$ & $139 \pm 110$ & $3.3 \pm 1.5$ \\
Undecorticated & 920 & $155 \pm 28$ & $236 \pm 06$ & $3.8 \pm 0.3$ \\
& 230 & $150 \pm 26$ & $335 \pm 47$ & $3.2 \pm 0.7$ \\
Average & 58 & $133 \pm 84$ & $134 \pm 37$ & $2.7 \pm 0.5$ \\
\hline \hline
\end{tabular}

Table 4

When evaluating 230- $\mathrm{gg}$ and $920-\mu \mathrm{g}$ implanted sites only, the undecorticated specimens were stiffer than decorticated ones in the coronal plane $(P=0.05)$. Stiffness to coronal bending, however, also was related to the dose of rhBMP-2 implanted $(P=0.03)$. Mechanical differences between decorticated and undecorticated fusions were not noted in other planes of motion (axial torque, $P=0.14$; sagittal bending, $P=0.29$ ). Further, differences were not noted when individual doses were evaluated.

\section{Histologic Examination}

Remnants of the polymeric carrier (OPLA) were noted in several specimens (Figure 5). The presence of OPLA was not related to the presence or absence of decortication. Inflammatory reaction, consisting of round cells and multinucleated giant cells, was noted in several specimens but was not related to the amount of residual polymer, the dose of rhBMP-2, or the condition of the host cortex. The degree of inflammatory response, however, appeared to be inversely related to the volume of de novo bone. 


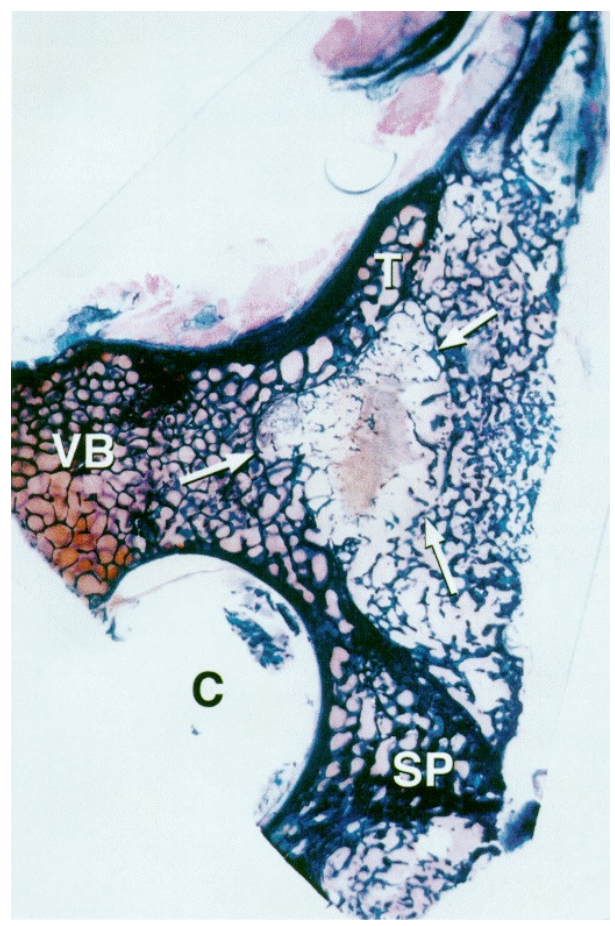

$\underline{\text { Figure } 5}$

Sections through radiographically noted void areas within de novo bone did not show evidence of local inflammatory response, but did show scant evidence of fatty marrow elements. Surrounding bone appeared to be relatively quiescent, with normal-appearing lamellar and woven bone. There was no evidence of local osteolysis.

The presence of de novo bone was seen in all specimens, but in varying abundance. Lamellar and woven bone were present in most specimens. In several cases, a "pseudo-cortex" was observed extending from the anterior cortices of the transverse processes across the intertransverse space (Figure 6). Bone formation occurred posterior to this cortical line, but a pseudo-cortex on the posterior surface of this bone mass was generally not present. Histologic estimation of uninterrupted transverse process bridging, when possible, correlated well with the clinical (manually tested) grading of fusion. 


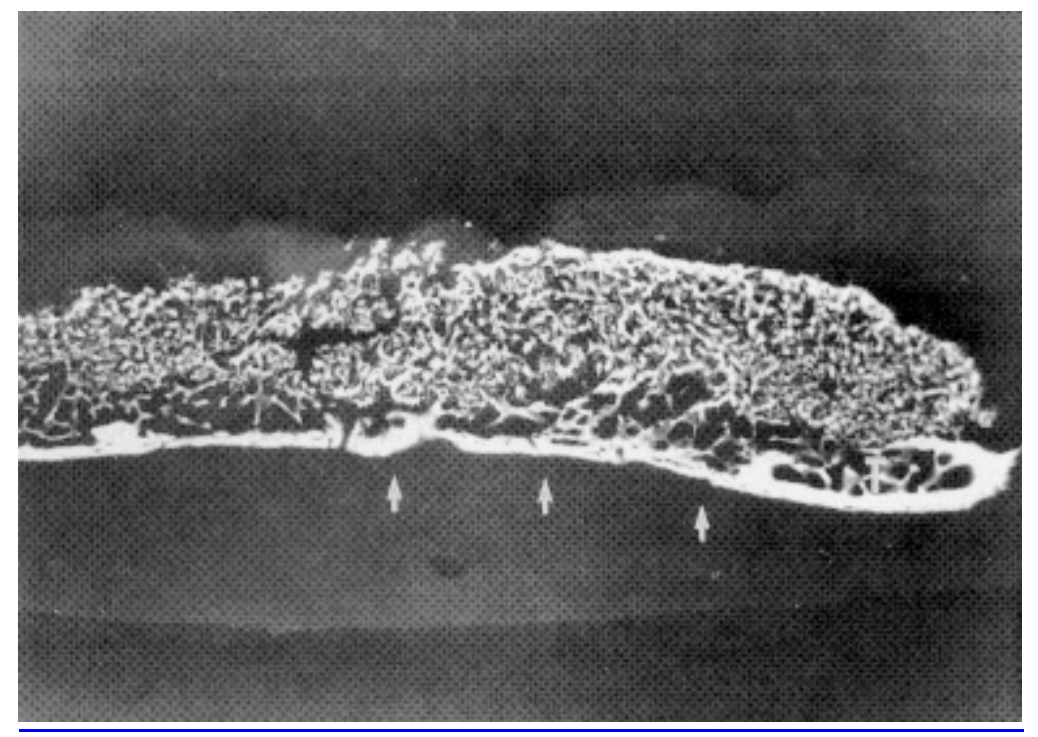

Figure 6

Continuity of de novo bone with originally undecorticated transverse processes was evident (Figure 7A) in the two higher-dose groups. When this occurred, the histologic appearances were indistinguishable from fusions seen in decorticated specimens (igure 7B). In the specimens implanted with the lowest dose of rhBMP-2, however, continuity between fusion mass and transverse process was not seen despite one specimen having radiographic and gross evidence of fusion. It is unclear whether continuity existed more centrally along the lamina and facet joints in this case.
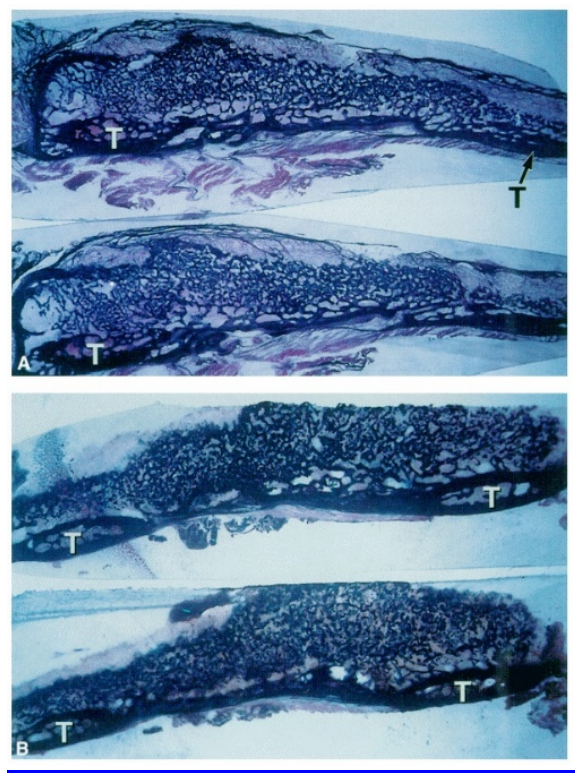

Figure 7 


\section{Discussion}

Ishikawa et al 7 have demonstrated that decortication is not an absolute prerequisite for successful spinal arthrodesis under particular circumstances. Segmentally instrumented rabbit spines receiving autologous iliac crest graft without decortication had histologic evidence of ossification of the fibrocartilaginous zone between bone graft and posterior elements, resulting in complete intersegmental osseous union. The fusion rates were not statistically different from those in animals that had been decorticated. In the absence of rigid instrumentation, however, undecorticated spines had much lower rates of fusion than decorticated spines.

The theoretical advantages of decortication are centered on the release of marrow elements into the fusion site. It is speculated that osteoinductive cytokines present in marrow are released by cortical disruption. Additionally, the initial hematoma serves as an osteoconductive vehicle to distribute these inductive proteins throughout the tissue volume and fusion bed. 4 Finally, marrow is considered a source of uncommitted mesenchymal stem cells that, once differentiated, can give rise to bone, cartilage, tendon, ligament, muscle, or marrow stroma. $\underline{10}$ After decortication, as in fracture repair, these stem cells are directed by osteoinductive cytokines to differentiate into bone-forming cells, leading to osteogenesis and bone healing.

It is generally accepted, however, that uncommitted mesenchymal stem cells can be derived from muscle and periosteum in addition to bone marrow. $2,9,15,18$ The relative contributions of stem cells from these sources and the location of their descendants during routine fracture repair are areas of very active research. Nonetheless, the presence of target cells responsive to osteoinductive molecules in extraskeletal connective tissue is consistent with the ability of rhBMP-2 to induce de novo cartilage and bone in ectopic sites. $\underline{17}$ It also provides a biologic mechanism by which cortical disruption may not be essential for generation of intersegmental arthrodesis. It is on this premise that the current study was conducted.

In a previous study using this model, two dogs underwent decortication of the posterior elements and implantation of the same polylactic acid delivery vehicle, but without rhBMP-2. $\frac{11}{1}$ By 3 months, there was no evidence of de novo bone formation by quantitative CT in the intertransverse process space and certainly no evidence of radiographic or clinical fusion. Consequently, decortication and implantation of carrier alone does not yield a positive outcome with this model (negative control).

Although the decorticated and undecorticated groups in this study differed in average age at the time of surgery, the authors do not believe that this was a significant factor because all animals were skeletally mature. Further, because the undecorticated dogs were older, the bias, if any, would have favored the decorticated (control) condition.

The data clearly demonstrate that it is feasible, in the presence of rhBMP-2, to achieve solid intersegmental transverse process arthrodesis without decortication or exposure of marrow elements. In fact, in the two higher dose groups, all dogs achieved fusion radiographically and clinically, regardless of whether the posterior elements were decorticated. When implanted with the $58-\mu \mathrm{g}$ dose of rhBMP-2, however, decorticated and undecorticated dogs exhibited instances of radiographically 
incomplete fusion. The only instance of a clinically failed fusion was in an undecorticated specimen implanted with the $58-\mu \mathrm{g}$ dose, but this was not statistically significant.

Radiographically, abundant de novo bone was noted along the plane of the L4 and L5 lamina even though the implants were deliberately placed laterally along the transverse processes. The amount of bone was not related to the presence or absence of decortication. Despite the central extension of fusion mass in both conditions, there was no evidence of spinal canal or foraminal encroachment, nor was there evidence of extension of fusion mass to adjacent levels. Considerable care was taken to avoid inadvertent exposure of adjacent levels during surgical dissection and, quite possibly, this may have been responsible for containment of the fusion mass to the isolated motion segment. Clinically, however, restriction of surgical exposure may not be practical or feasible. It generally is believed that containment of bone morphogenetic protein-induced bone formation will ultimately be the responsibility of the cytokine delivery system. Cytokine delivery, particularly for the osteoinductive growth factors, is currently a very active area of research but was not the subject of the current study and was not addressed further.

In few instances, radiolucent areas, or void areas, were noted radiographically within de novo bone but were histologically quiescent. There was occasional evidence of marrow fat, suggesting the formation of a marrow cavity similar to that reported by Urist $\underline{15}$ in his ectopic bone assays; however, there was not sufficient nor consistent evidence to confirm this. Surrounding areas contained bone that appeared normal with no evidence of osteolysis or inflammatory reaction.

With mechanical testing, there were no overall differences in fusion stiffness between the decorticated and undecorticated spines. When the lowest dose specimens were excluded, there was greater stiffness to coronal bending in the undecorticated specimens. Coronal bending stiffness was more correlated to rhBMP-2 dose, however, than to the condition of the host cortex.

The ability to achieve undecorticated spinal fusion with rhBMP-2 in this model was confirmed by histologic examination. When either the $230-\mu \mathrm{g}$ or the $920-\mu \mathrm{g}$ dose of rhBMP-2 was delivered, the fusions obtained with or without decortication were difficult to differentiate. Ossification was generally contiguous between de novo bone and host bone. The fact that this was not seen with the 58- $\mu$ g dose suggests that the minimum effective dose of rhBMP-2 in this fusion model without decortication may lie somewhere between $58 \mu \mathrm{g}$ and $230 \mu \mathrm{g}$. It is plausible that the benefit of decortication is to lower the minimum effective dose of rhBMP-2, perhaps by releasing additional osteoinductive cytokines from bone marrow. Whether or not this is the case, when sufficient doses of inductive factor are used, decortication of posterior elements does not afford any added benefit in this model.

Whether the findings of this study will translate to higher vertebrates is unknown. It has been suggested that mammals higher on the evolutionary scale, such as nonhuman primates, lack the

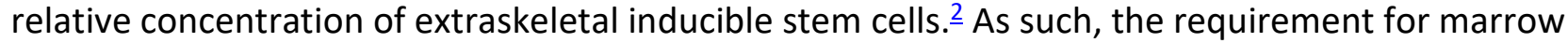
elements, or lack thereof, in the fusion bed of a higher vertebrate may be entirely different than that of a lower vertebrate. Nonetheless, the results of this study, that the dose of rhBMP-2 delivered was a better predictor for successful fusion than host bone preparation, suggest that this issue requires further exploration. 


\section{Conclusion}

The availability osteoinductive proteins such as rhBMP-2 has opened a new era of invasive biologic intervention for musculoskeletal disease. Lower vertebrate mammalian models previously have established efficacy of rhBMP-2 for inducing transverse process spinal fusions and for healing of segmental long bone defects. These results were obtained with conventional techniques for autologous bone graft-induced osteogenesis. This study suggests that, in the presence of potent osteoinductive factors, the biologic environment around a fusion site may be sufficiently altered such that conventional rules for fusion surgery no longer may be applicable. Further evaluation of the need for decortication for spinal fusion in higher vertebrates is recommended.

\section{Acknowledgment}

The authors thank John Brekke, DDS, of THM Biomedical, Inc. for his scientific consultation regarding OPLA and Jennifer Smith, PhD, and John Wozney, PhD, of Genetics Institute, Inc. for their scientific consultation regarding rhMBP-2. They thank undergraduate student research program participants Lily Ghafouri, Ito "Sharon" Nagakawa, and Cindy Luppen for their valued assistance.

\section{References}

1. Allen BL Jr, Ferguson RL. Basic consideration in pelvic fixation cases. In: Luque ER, ed. Segmental Spinal Instrumentation. Thorofare, NJ: Charles B. Slack, Inc., 1984;185-220.

2. Aspenberg P, Wang E, Thorngren KG. Bone morphogenetic protein induces bone in the squirrel monkey, but bone matrix does not. Proc Orthop Res Soc 1993;39:101.

3. Cambell WC. An operation for extra articular arthrodesis of the sacroiliac joint. Surg Gynecol Obstet 1927;45:218-9.

4. Cruess RL. Healing of bone tendon and ligament. In: Rockwood CA, Green DP, eds. Fractures. Philadelphia: J.B. Lippincott, 1984:153.

5. Friedenstein AJ, Petrakova KV, Kurolesova AI, Frolova GP. Heterotopic transplants of bone marrow: Analysis of precursor cells for osteogenic and hemopoietic tissues. Transplantation 1968;6:23047.

6. Hibbs RA. Scoliosis treated by fusion operation. J Bone Joint Surg [Am] 1924;6:3-37.

7. Ishikawa S, Shin HD, Bowen R, Cummings RJ. Is it necessary to decorticate segmentally instrumented spines to achieve fusion. Spine 1994;19:1686-90.

8. Keene JS, McKinley NE. Iliac crest versus spinous process grafts in posttraumatic spinal fusions. Spine 1992;17:790-4.

9. Lucas PA, Syftestad GT, Goldberg VM, Caplan Al. Ectopic induction of cartilage and bone by watersoluble proteins from bovine bone using a collagenous delivery vehicle. J Biomed Mater Res 1989;23 (Suppl):23-39.

10. Muschler GF, Lane JM, Dawson KG. The biology of spinal fusion. In: Cotler JM, Cotler HB, eds. Spinal Fusion: Science and Technique. New York: Springer-Verlag, 1990:9-21. 
11. Sandhu HS, Kanim LEA, Kabo JM, et al. Evaluation of rhBMP-2 with an OPLA carrier in a canine posterolateral (transverse process) spinal fusion model. Spine 1995;20:2669-82.

12. Schimandle JH, Boden SD, Hutton WC. Experimental spinal fusion with recombinant human bone morphogenetic protein-2. Spine 1995;20:1326-37.

13. Urist MR, Mikulski A, Lietze A. Solubilized and insolubilized bone morphogenetic protein. Proc Natl Acad Sci USA 1979;76:1828-32.

14. Urist MR. Bone: Formation by autoinduction. Science 1965;150:893-9.

15. Urist MR. The search for and discovery of bone morphogenetic protein (BMP). In: Urist MR, O'Conner BT, Burwell RG, eds. Bone Grafts, Derivatives, and Substitutes. London: Butterworth Heinemann, 1994:315-62.

16. Wang EA, Rosen V, Cordes $P$, et al. Purification and characterization of other distinct bone inducing factors. Proc Natl Acad Sci USA 1988;85:9484-8.

17. Wang EA, Rosen V, D'Alessandro JS, et al. Recombinant human bone morphogenetic protein induces bone formation. Proc Nat Acad Sci USA 1990;87:2220-4.

18. Wozney JM. The bone morphogenetic protein family and osteogenesis. Mol Reprod Dev 1992;32:160-7. 